\title{
Paraganglioma of the Cauda Equina
}

\author{
Miguel Gelabert-González, Lara Pita-Buezas, Eduardo Arán-Echabe \\ University of Santiago de Compostela (Spain), Santiago de Compostela, Spain
}

We would like to make the following observations, on the basis of our personal experience ${ }^{3)}$, in relation to the recent article by San $\mathrm{OH}^{5)}$ Spinal paraganglioma adherent to the cauda equina.

Firstly, we do not share the assertion of authors: "Locations in the cauda equina are exceptional"; in our review published in 2005 about previously 174 reported cases of lumbar paragangliomas, 57 patients (33.9\%) had their tumor adhered to the cauda equina ${ }^{3)}$.

Secondly, the authors indicate that ependymomas are classified as WHO grade II-III, however, more than $90 \%$ of ependymomas located in the cauda equina-filum terminale are mixopapyllary (WHO grade I) ${ }^{2,4)}$.

Thirdly, we agree with the authors that the differential diagnosis must be made with ependymomas of the filum terminal, but also with other tumors in the same location as schwannomas and meningiomas. Paragangliomas are usually hypo- or isointense to the conus medullaris on T1-weighted sequences, whereas it is hyperintense on T2-weighted sequences, sometimes inhomogeneous, and in some cases cystic areas have been reported. After Gd injection, there was marked enhancement; in other cases a serpiginous area of flow voids was observed, which suggested vessels capping the tumor. Araki, et al. ${ }^{1)}$, suggested that this sign is a major clue to the diagnosis of a highly vascular lesion. Hypointense tumor margins on T2-weighted MR and proton-density imaging may indicate hemosiderin or ferritin from previous hemorrhages. It is dificult to distinguish paragangliomas from meningiomas and schwannomas because the latter are all hypo- or isointense with respect to the spinal cord on T1-weighted and iso- or hyperintense on T2-weighted images. Postcontrast enhancement, however, is homogeneous in schwannoma and meningioma, and no report of a low- intensity band or hemosiderin rim has been documented by MR imaging in cases of these tumors. Moreover, pre- operatively paragangliomas can be differentiated from these tumors based on the presence of hemorrhage and cyst formation in schwannoma and calcification in meningioma? .

\section{REFERENCES}

1. Araki Y, Ishida T, Ootani M, Yamamoto H, Yamamoto T, Tsukaguchi I, et al: MRI of paraganglioma of the cauda equina. Neuroradiology 35:232-233, 1993

2. Bagley CA, Wilson S, Kothabauer MJ, Epstein F, Jallo GI: Long term outcomes following surgical resection of myxopapillary ependymomas. Neurosurg Rev 32:321-334, 2009

3. Gelabert-González M: Paragangliomas of the lumbar region. Report of two cases and review of the literature. J Neurosurg Spine 2:354-365, 2005

4. Gelabert-González M, Arcos-Algaba A, Serramito-García R, Castro-Bouzas D, Santín-Amo JM, Aran- Echabe E, et al: Filum terminale ependymomas. Analysis of a serie of 20 consecutive cases. Neurocirugía (Astur) 21:381-389, 2010

5. Oh HS, Kim TW, Park KH: Spinal paraganglioma adherente to the cauda equina. Korean J Spine 11:252-254, 2014

6. Taira H, Takasita M, Yoshida S, Takita C, Tsumura H, Torisu $\mathrm{T}$ : MR appearance of paraganglioma of the cauda equina. Case reports. Acta Radiol 41:27-30, 2000.

\footnotetext{
- Received: January 25, 2015 - Revised: February 10, 2015

- Accepted: February 11, 2015

Corresponding Author: Miguel Gelabert-González, MD

University of Santiago de Compostela (Spain), San Francisco 1,

Santiago de Compostela, Spain

Tel: +34981950331, Fax: + 34981950404

E-mail: miguel.gelabert@usc.es

@This is an Open Access article distributed under the terms of the Creative

Commons Attribution Non-Commercial License (http://creativecommons.org/

licenses/by-nc/3.0/) which permits unrestricted non-commercial use, distribution,

and reproduction in any medium, provided the original work is properly cited.
}

Copyright (C) 2015 The Korean Spinal Neurosurgery Society 